\title{
Do diagnóstico às questões avaliativas: um caminho possível via prática de avaliação em educação a distância
}

\author{
Ângela Carrancho da Silva* \\ - Christina Marília Teixeira da Silva**
}

\section{Resumo}

0 artigo apresenta resultados parciais de uma avaliação diagnóstica da Educação Superior a Distância no País. Esse estudo foi desenvolvido na disciplina Prática de Avaliação oferecida no Mestrado Profissional em Avaliação da Fundação Cesgranrio. A partir do levantamento do estado da arte da Educação a Distância, foram elaboradas questões avaliativas que servirão de fio condutor a futuras práticas avaliativas do Curso.

Palavras-chave: Avaliação. Educação a distância. Prática de avaliação. Mestrado Profissional em Avaliação.

\section{From diagnosis to evaluation questions: a possible way through evaluation practice of the long-distance education Abstract}

This article presents partial results of a diagnostic evaluation of LongDistance Higher Education in Brazil. This study was developed in the Evaluation Practice course offered by the Professional Master Course in Evaluation at Cesgranrio Foundation. Based on the state of art of LongDistance Education, evaluative questions were developed, which will become reference to the future evaluative practices of the program.

Keywords: Evaluation. Long-Distance Education. Evaluation practice. Professional Master Course in Evaluation

\footnotetext{
* Doutora em Educação, Ciência e Tecnologia, Universidade Estadual de Campinas (Unicamp); Profa. da UERJ; Profa. do Mestrado Profissional em Avaliação da Fundação Cesgranrio. E-mail: angelacarrancho@globo.com

** Doutora em Engenharia de Produção, UFRJ; Profa. do Mestrado Profissional em Avaliação da Fundação Cesgranrio. E-mail: christina@cesgranrio.org.br
} 


\section{Del diagnóstico a las cuestiones evaluativas: un camino posible vía práctica de evaluación en educación a distancia. Resumen}

Este artículo presenta resultados parciales obtenidos en una evaluación diagnóstica de la Educación a Distancia en cursos superiores brasileños. Esta investigación fue desarrollada en la signatura Práctica de Evaluación ofrecida por el Curso de Maestría Profesional en Evaluación de la Fundación Cesgranrio. Cuestiones evaluativas fueran desarrolladas con base en el estado del arte de la Educación a Distancia y servirán como referencia de las futuras prácticas evaluativas del programa.

Palabras clave: Evaluación. Educación a distancia. Práctica de evaluación. Curso de Maestría Profesional en Evaluación.

\section{Introdução}

0 Mestrado Profissional em Avaliação da Fundação Cesgranrio, aprovado pela CAPES em 12 de julho de 2006 e de característica multidisciplinar, visa à formação de profissionais de avaliação capazes de planejar, conduzir, relatar e utilizar a avaliação de sistemas, de programas, de instituições e de materiais. Seu público-alvo são profissionais graduados em diferentes áreas, atuando em Secretarias de Educação e instituições de ensino, em órgãos públicos e particulares, em empresas, programas sociais e organizações não governamentais, e demais graduados com potencial, motivação e interesse de formação na área de avaliação.

0 Mestrado, com duração de 18 meses, tem como área de concentração a avaliação de sistemas, programas e instituições. Suas linhas de pesquisa são: avaliação de sistemas e programas; abordagens e metodologias de avaliação; e avaliação das tecnologias de informação e comunicação. 0 Curso contempla disciplinas obrigatórias e eletivas, assim como atividades práticas de avaliação, em que o mestrando trabalha junto com o pesquisador/avaliador em projetos de avaliação ligados tanto aos grupos de pesquisa do programa, quanto aos projetos desenvolvidos pela Fundação Cesgranrio.

Neste artigo são apresentados os resultados da primeira etapa da Disciplina Prática de Avaliação em Educação a Distância. Nesta Prática são trabalhadas algumas competências que o avaliador deve dominar, a saber: (a) comunicação oral, escrita e visual; (b) habilidades interpessoais; (c) comportamento ético e legal; (d) estratégias para obtenção dos dados necessários; (e) coleta de dados; (f) análise e interpretação dos dados coletados; e (g) elaboração de relatórios e artigos (IBSTPI, 2006). 
A necessidade sentida pelas professoras, em oferecer uma Prática de Avaliação voltada para a educação on-line, deve-se ao fato de que as mesmas têm observado que ainda restam muitos desafios a serem superados nesse setor. Assim, apesar de os ambientes virtuais de aprendizagem contarem com ferramentas computacionais capazes de promover o processo de construção do conhecimento, o tradicionalismo das abordagens educacionais usadas nesses ambientes, assim como as exigências da legislação pertinente, contribuem para que os Cursos Superiores on-line no Brasil, de forma geral, subutilizem os recursos tecnológicos disponiveis (SILVA, C. M. T.; SILVA, A. C., 2008). Apesar desse quadro, o acelerado crescimento da oferta de Cursos Superiores a distância indica haver uma expressiva demanda por parte de pessoas que necessitam aprimorar sua formação de maneira não presencial. A respeito da expansão dos cursos on-line, Laguardia, Portela e Vasconcellos (2007, p. 516) alertam:

No Brasil, a exiguidade de estudos avaliativos das experiências em EAD tem limitado a constituição de um conhecimento mais aprofundado sobre a adequação das abordagens pedagógicas, os custos de investimento em tecnologia, especialmente nas modalidades virtuais, assim como os fatores associados, diretamente ou não, ao desempenho dos alunos.

A Prática contempla as seguintes etapas: (a) levantamento dos Cursos de Graduação desenvolvidos em plataformas virtuais, no âmbito público e privado, no País; (b) levantamento, junto a Secretaria de Educação a Distância (SEED), do Ministério da Educação (MEC), dos polos de Educação a Distância (EAD); (c) levantamento das avaliações dos Cursos de Graduação a distância; (d) formulação de questões avaliativas oriundas dos levantamentos desenvolvidos; e (e) elaboração de relatórios parciais apresentando resultados referentes a cada etapa do estudo avaliativo.

Os procedimentos metodológicos adotados na disciplina Prática de Avaliação foram organizados em diversas etapas. Na primeira delas foram apresentados, ao grupo de discentes inscritos, os objetivos da Prática de Avaliação em EAD. Neste momento, foram também discutidas as competências do avaliador a serem trabalhadas.

A seguir, na segunda etapa, foi discutido o referencial teórico a ser lido e analisado, assim como foram divididos os grupos e as tarefas a serem desenvolvidas para a etapa seguinte do estudo avaliativo. Neste momento foi também elaborado um cronograma de ações presenciais e de atividades a serem desenvolvidas de forma virtual. A turma foi dividida em cinco grupos com a finalidade de coletar e organizar os dados referentes à oferta de Educação Superior Pública a Distância em cada região geográfica do País.

$\mathrm{Na}$ terceira etapa, cada grupo apresentou os dados coletados e organizados por Região. Os dados coletados na terceira etapa foram reorganizados em gráficos e tabelas e levantadas as primeiras questões avaliativas. 
A quarta etapa ficou destinada à elaboração de um Blog1 para que as informações pudessem ser veiculadas de forma mais rápida e clara, facilitando a comunicação entre discentes e docentes, abrindo um canal virtual para a Prática de Avaliação.

$\mathrm{Na}$ última etapa deste estudo avaliativo, respondeu-se às questões iniciais e foram levantadas novas questões a serem trabalhadas em momentos futuros.

Como resultado das atividades desenvolvidas no ano de 2008 pelas professoras e pelos alunos matriculados nesta Prática, foi publicado um livro (SILVA, A. C.; SILVA, C. M. T., 2008), o primeiro de uma série a ser elaborada passo a passo.

No presente artigo são apresentados alguns conceitos e definições sobre a chamada Educação a Distância. A seguir, são fornecidos os dados sobre os Cursos de Graduação a Distância no setor público, provenientes do levantamento realizado na Prática de Avaliação. Na penúltima parte do artigo são propostas algumas questões avaliativas surgidas durante as fases divergente e convergente deste estudo avaliativo. Finaliza-se o trabalho tecendo algumas considerações ainda não definitivas, mas que, de certa forma, finalizam esta etapa do estudo.

\section{0 que é Educação a Distância afinal?}

Não se pode negar o evidente crescimento da chamada Educação a Distância no Brasil, principalmente no Ensino Superior. Dentre as principais razões para esse crescimento, destaca-se a demanda reprimida de alunos não atendidos neste segmento. A Lei de Diretrizes e Bases da Educação Nacional, Lei no 9.394 (BRASIL, 1996), de 20 de dezembro de 1996, normatizou o Ensino Superior a distância pela primeira vez no País.

Ao mesmo tempo em que se percebe um aumento significativo da oferta de vagas desta modalidade de ensino no País, nota-se também, que a chamada EAD sempre esteve vinculada ao ensino técnico, desde a década de 40, com o Instituto Monitor e o Instituto Universal Brasileiro. Depois se vinculou ao ensino de adultos - os antigos supletivos - com os Telecursos. Pode-se dizer que a chamada Educação a Distância no Brasil está dividida em três gerações. A primeira geração foi marcada pela correspondência, onde o serviço postal era a grande ferramenta. Na segunda geração - era dos multimeios, o texto impresso, a radiodifusão, o telefone e o fax atuavam como as grandes ferramentas disponiveis para esta modalidade. A terceira geração, ou aquela que estamos vivenciando, é marcada pelo sistema digital que integra a televisão, o computador, as salas virtuais, os sistemas de áudio e videoconferências e a Internet.

A década de 90 trouxe ao cenário brasileiro uma série de modificações no campo educacional, abrindo espaço para alternativas ao modelo presencial, único

1 Disponivel em: <http://www.mestradocesgranrio.blogspot.com/>. Acesso em: 22 jun. 2009. 
até então legalizado no País. Entretanto, embora a legislação tenha normatizado esta modalidade de ensino, o seu conservadorismo revela que o modelo proposto com o nome de Educação a Distância é, na verdade, semipresencial. De acordo com a Lei no 9.394 (BRASIL, 1996),

A avaliação do desempenho do estudante para fins de promoção, conclusão de estudos e obtenção de diplomas ou certificados dar-se-á no processo, mediante:

I - cumprimento das atividades programadas; e

II - realização de exames presenciais.

$\S 2^{\circ}$ Os resultados dos exames citados no inciso II deverão prevalecer sobre os demais resultados obtidos em quaisquer outras formas de avaliação a distância.

Assim, a legislação brasileira inviabiliza qualquer projeto de Educação integralmente a distância. Embora estejamos vivenciando a terceira geração, no que se refere à possibilidade de cursos sediados em plataformas virtuais, o cotidiano nos oferece modelos que travestidos pela nomenclatura de a distância, são, na verdade, cursos semipresenciais. Tais cursos, mesmo que oferecidos através de plataformas virtuais e apresentando algum nivel de interatividade pela infovia, demandam a presença física do estudante em momentos de avaliação.

A geração mais recente da chamada educação a distância, atualmente chamada de educação on-line, é um modelo veiculado exclusivamente pela Internet e redes digitais. Neste modelo, o aluno se conecta a uma plataforma virtual e lá faz o seu caminho em busca dos materiais disponibilizado pelas coordenações. 0 estudante também tem acesso à orientação dada por seus professores, e a diferentes niveis de interatividade com colegas de turma, coordenadores, professores, dentre outros. Cada curso, nesta modalidade, oferece diferentes propostas pedagógicas, variando em um continuum desde desenhos completamente fechados a propostas mais progressistas, onde existem diferentes niveis de interatividade e maior colaboração nas atividades pedagógicas.

Hoje há muitas opções de plataformas virtuais que disponibilizam, ao usuário, as mais variadas possibilidades de ferramentas, para um processo ensino-aprendizagem mais compatível com a virtualidade. É possivel desenhar-se programas síncronos ou assíncronos, centrados em conteúdos ou em projetos, enfim, a metodologia vai depender do projeto pedagógico de cada Curso e de cada Instituição. Entretanto, a legislação brasileira ainda exige a presença física do estudante em momentos de avaliação. Dessa forma, a avaliação, mesmo que em cursos on-line, ainda segue os modelos planejados para a Educação Presencial. Ou seja, a chamada "Educação a Distância" no Brasil, é, na verdade, um modelo semipresencial. 
Embora discordemos da nomenclatura "Educação a Distância", por entendê-la já ultrapassada, estamos nesse estudo utilizando-a por força da lei. Deixamos aqui algumas questões que, certamente, encontram-se respondidas ao longo deste trabalho: existe, de fato, distância em cursos oferecidos por plataformas virtuais? Qual a distância existente na virtualidade? É possivel continuarmos a usar os mesmos paradigmas de tempo e espaço em ambientes virtuais?

\section{Cursos de graduação a distância no Brasil: a rede pública}

Nessa seção são apresentados os Cursos de Graduação da Rede Pública na modalidade dita a distância em todo o País. Para facilitar a visualização e possíveis análises do estado da arte desta modalidade educacional no cenário brasileiro, optou-se por organizar os dados por região geográfica. Em cada região são destacados as Instituições Superiores de Ensino e os cursos oferecidos, com o respectivo número de vagas.

Desde a sua primeira concepção, que levou o nº. 962, em 1972, o projeto de Lei da Universidade Aberta no Brasil (UAB) passou por muitos caminhos e descaminhos. Entre arquivamentos e desarquivamentos, o projeto finalmente ganha incentivo legal com a Lei no. 9.394 (BRASIL, 1996) e, em 2005, com a criação da UAB. Na verdade, a UAB não é uma universidade, mas sim um consórcio de instituições públicas de Ensino Superior.

Vale ressaltar que, embora tenha o nome de Universidade Aberta, não segue as diretrizes norteadoras do documento que legisla sobre a criação e o funcionamento da Open University, criada na Inglaterra no início dos anos 70. 0 modelo brasileiro de Open University se diferencia do modelo inglês, entre outros aspectos, no que diz respeito à frequência. Por exemplo, a experiência inglesa não exige frequência às aulas, a não ser uma ou duas semanas por ano. Além disso, o modelo inglês está aberto a todo cidadão maior de 21 anos, independente do nivel de escolaridade anterior, e também não há exame de admissão. Finalmente, o termo "aberta" do modelo inglês está diretamente ligado à franquia dos cursos oferecidos pelo rádio e pela televisão para o público em geral.

Embora a criação da UAB constitua um grande ganho para o cenário da educação no Pais, mais uma vez nota-se que a nomenclatura que envolve este sistema apresenta uma série de equivocos: universidade aberta que não é aberta; educação a distância que não é a distância, enfim a terminologia tem-se mostrado não reveladora do real modelo deste sistema. Entretanto, apesar dos ranços, não se pode negar que são muitos também os avanços neste setor e que muitos passos têm sido dados no sentido de aumentar o quantitativo de pessoas atendidas por esta modalidade de educação em um País continente como o Brasil. 
De acordo com a Assessoria de Imprensa da Fundação Coordenação de Aperfeiçoamento de Pessoal de Nivel Superior (Capes), em maio de 2008 foram ofertadas 40 mil vagas para formação de professores distribuídas em 271 novos polos (CAPES, 2008a). Celso Costa, atual diretor de EAD da Capes (2008b) e coordenador da UAB, informa que o objetivo é fazer com que cada polo atenda à população num raio de 120 quilômetros. A Assessoria de Comunicação do MEC informa que nos polos é oferecida toda a infraestrutura necessária para as atividades presenciais dos cursos, como laboratório de informática e biblioteca. Além disso, os polos também oferecem uma equipe de tutores para auxiliar os estudantes em seus estudos. Ainda de acordo com informação contida na página da UAB, a Universidade Aberta possui 356 cursos superiores, 75 IES atuando em 560 polos. São 2436 cursos articulados atendendo a 100 mil alunos em 2008. A UAB ofereceu também 60 cursos de especialização em 2008. Apresenta-se, a seguir, o cenário da Educação a Distância por Região Brasileira².

\section{A Região Norte}

A região Norte é formada por sete estados: Acre, Amapá, Amazonas, Pará, Rondônia, Roraima e Tocantins. Está localizada na região geoeconômica da Amazônia entre o Maciço das Guianas (ao norte), o planalto Central (ao sul), a Cordilheira dos Andes (a oeste) e 0 oceano Atlântico (a nordeste).0 clima da região é predominantemente equatorial com exceção do norte do Pará, do sul do Amazonas e de Rondônia, onde o clima é tropical.

A região abriga a maior bacia hidrográfica do mundo, e, apesar de contar com grandes usinas hidrelétricas, o seu maior problema continua sendo a escassez de energia. Grande parte da área ainda depende de geradores movidos a óleo diesel. Embora a maioria dos rios da região seja navegável, os problemas de comunicação e transporte de mercadorias são enormes.

A Amazônia é muito importante para o ambiente do planeta, pois ela fixa 0 carbono da atmosfera, através do crescimento das plantas e da fotossintese, reduzindo, assim, o efeito estufa.

No campo da Educação, os índices têm apontado para resultados nada gratificantes. Em 2007, 160 municípios da Região Norte encontravam-se entre aqueles que obtiveram as mais baixas pontuações no Índice de Desenvolvimento da Educação Básica (Ideb). Os desafios da educação na região vão da escassez de recursos às grandes distâncias. Uma das maiores dificuldades é garantir o transporte escolar. $\mathrm{Na}$ região há alunos que viajam horas de barco para chegar à escola. A região se caracteriza, ainda, por altos indices de analfabetismo e por um número significativo de professores sem formação atuando nos diversos niveis da educação básica, o que contribui para o baixo rendimento do seu sistema escolar.

2 Parte das informações referentes às Regiões Brasileiras foi obtida no site Portal Brasil (2008). 
As grandes extensões territoriais pouco povoadas, o isolamento de algumas cidades, a falta de transporte, a falta de profissionais para atender à demanda são alguns possiveis indicadores dos baixos índices de escolaridade da região. Com relação ao Ensino Superior, as universidades federais se constituem, em alguns casos, na única possibilidade de acesso a este nível educacional: 64\% dos alunos matriculados no Ensino Superior estão nas instituições federais de ensino superior (no sistema brasileiro como um todo, esse percentual é de apenas 22\%).

Na Região Norte, as instituições participantes da UAB no atendimento ao programa de EAD são: Universidade Federal do Amazonas (UFAM), Universidade Federal do Pará (UFPA), Centro de Educação Tecnológica do Pará (CEFET-PA), Universidade Federal de Roraima (UFRR), Universidade Federal do Tocantins (UFT), e Fundação Universidade Federal de Rondônia (UNIR).

A distribuição das vagas por Curso de Graduação na Região Norte pode ser vista no Gráfico 1. Como se pode observar, o curso com maior oferta é o de Pedagogia. Os cursos seguintes - Biologia, Física, Matemática, Geografia, Ciências Agrárias e Artes Plásticas -, também são voltados para a formação de professores. Os cursos de Química e de Letras, embora tenham a finalidade de formar docentes, são os que oferecem menos vagas.

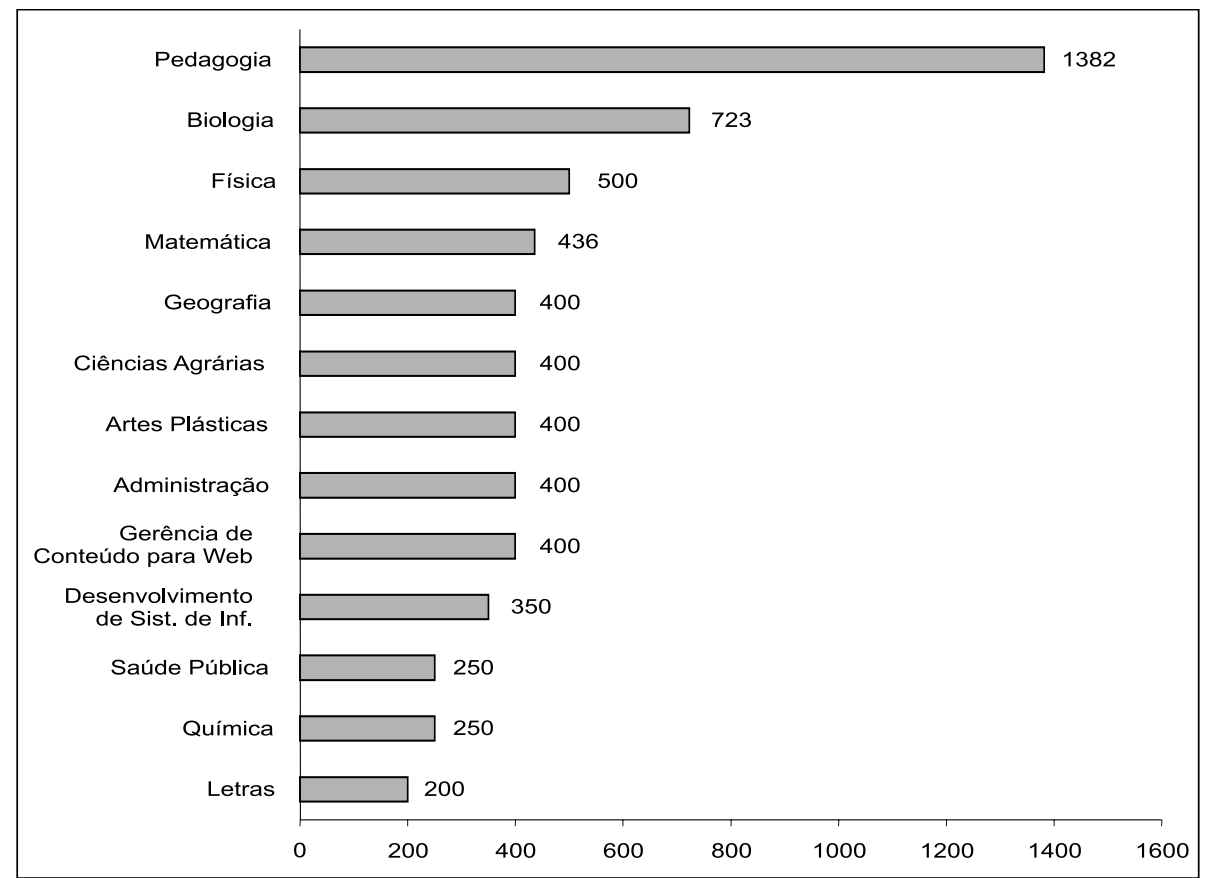

Gráfico 1 - Distribuição das vagas por curso na Região Norte. Fonte: As autoras (2008). 


\section{Região Nordeste}

A Região Nordeste é formada por 9 Estados e 1792 Municípios. Os Estados são: Alagoas, Bahia, Ceará, Maranhão, Paraiba, Pernambuco, Piauí, Rio Grande do Norte e Sergipe. A maior parte desta região está em um extenso planalto, que abriga 27,9\% da população brasileira. Em função das diferentes características físicas que apresenta, a região é dividida em sub-regiões: meio-norte, zona da mata, agreste e sertão.

Embora o Nordeste seja rico em recursos minerais como o petróleo e o gás natural, produzidos na Bahia, em Sergipe e no Rio Grande do Norte, ou como as jazidas de granito, pedras preciosas e semipreciosas, ou pelo gesso de Pernambuco, que responde por 95\% do total brasileiro, a região é a mais pobre do País: 50,12\% da população nordestina tem renda familiar de meio salário mínimo.

No que se refere à Educação Superior, a Região possui 52 Instituições de Ensino Superior Públicas e 252 instituições privadas. Os indicadores educacionais do Nordeste são os piores do Brasil. De acordo com dados do Instituto Nacional de Estudos e Pesquisas Educacionais Anísio Teixeira (INEP, 2008): "o Nordeste possui a maior taxa de analfabetismo do Pais, com quase oito milhões de analfabetos, o que corresponde a quase $50 \%$ do total do Brasil".

Na Região Nordeste as instituições participantes da UAB no atendimento ao programa de EAD são: Centro Federal de Educação Tecnológica de Alagoas (CEFET-AL), Universidade Federal de Alagoas (UFAL), Universidade Federal de Sergipe (UFSE), Centro Federal de Educação de Pernambuco (CEFET-PE), Universidade Federal de Pernambuco (UFPE), Universidade Federal Rural de Pernambuco (UFRPE), Universidade Federal da Paraiba (UFPB), Centro Federal de Educação Tecnológica do Rio Grande do Norte (CEFET-RN ), Universidade Federal do Rio Grande do Norte (UFRN), Centro Federal de Educação Tecnológica do Ceará (CEFET-CE), Universidade Federal do Ceará (UFCE), Universidade Federal do Piauí (UFPI, e Universidade Federal do Maranhão (UFMA).

A distribuição das vagas por Curso de Graduação na Região Nordeste é apresentada no Gráfico 2. Os cursos com maior oferta são os de Letras, Matemática e Sistemas de Informação. Apesar do predomínio de cursos cuja finalidade é a formação de professores, têm-se cursos como Sistemas de Informação e Administração disponibilizando um grande número de vagas. $\mathrm{Na}$ Região Nordeste é possível dividir a oferta de cursos em três grupos: as licenciaturas, com 6083 vagas, cursos tecnológicos na área de turismo, ambiental e computação e Bacharelado. 0 único curso de bacharelado é o de Administração, com 850 vagas. 


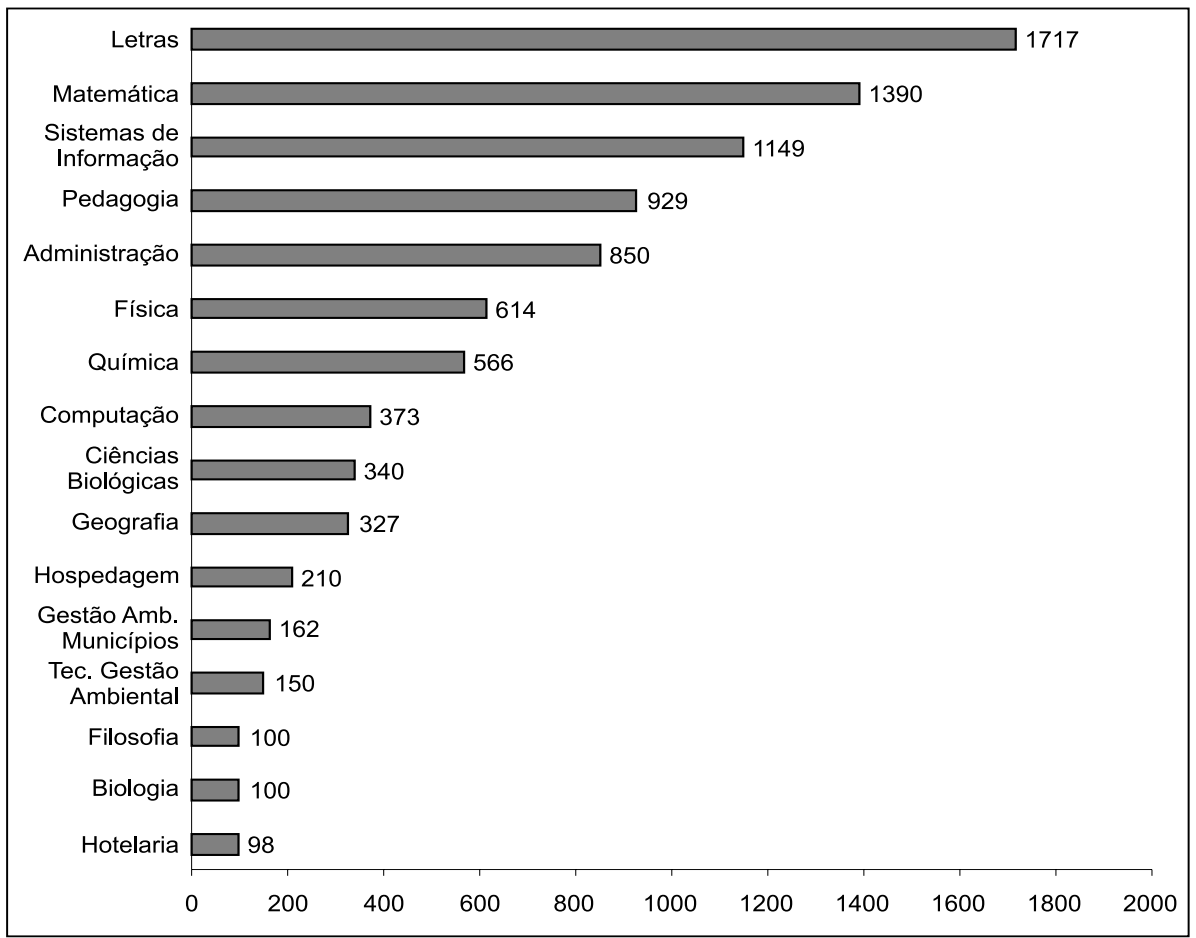

Gráfico 2 - Distribuição das vagas por curso na Região Nordeste. Fonte: As autoras (2008).

Embora a formação de professores seja a prioridade um do Governo atual, na região Nordeste há uma oferta de 2992 vagas, o que significa aproximadamente 33\% do quantitativo total oferecido, em áreas não priorizadas pelas atuais políticas públicas.

\section{Região Centro-Oeste}

A região Centro-Oeste engloba os estados de Goiás, Mato Grosso, Mato Grosso do Sul, o Distrito Federal, além de 463 municípios. A Região possui uma área de $1.612 .056 \mathrm{~km}^{2}$ e uma população de 12.770 .141 habitantes.

Em princípio, a economia da região foi baseada na exploração de garimpos de ouro e diamantes, sendo posteriormente substituída pela pecuária. A transferência da capital federal do Rio de Janeiro para Brasília e a construção de novas vias de acesso, aceleraram o povoamento, contribuindo para o seu desenvolvimento. A economia do Centro-Oeste cresce em um ritmo semeIhante ao do País. Isso faz com que a região tenha, desde 1991, uma participação de 7,2\% no PIB brasileiro, segundo o Instituto de Pesquisa Econômica Aplicada (IPEA), acima de US\$ 40 bilhões em 1999. 
A agroindústria é o setor mais importante da economia da região. Ela é a maior produtora de soja, sorgo, algodão em pluma e girassol. 0 Centro-Oeste possui também o maior rebanho bovino do País, principalmente em Mato Grosso do Sul.

As indústrias são, principalmente, do setor de alimentos e de produtos como adubos, fertilizantes e rações, além de frigorificos e abatedouros. As maiores reservas de manganês do País estão localizadas no maciço do Urucum, no Pantanal. 0 difícil acesso ao local dificulta a exploração dessas reservas.

Com relação ao Ensino Superior, a região possui 23 Instituições de Ensino Superior Públicas e 187 privadas. As públicas atendem a 114.649 estudantes, enquanto as particulares têm 254.257 estudantes matriculados.

Na Região Centro-Oeste, as instituições participantes da UAB no atendimento ao programa de EAD são: Universidade Federal de Mato Grosso (UFMT), Centro Federal de Educação Tecnológica do Mato Grosso (CEFET-MT), Universidade Federal de Goiás (UFG), Universidade de Brasilia (UnB), e Universidade Federal de Mato Grosso do Sul (UFMS).

A distribuição das vagas por Curso de Graduação na Região Centro-0este é mostrada no Gráfico 3. Observa-se que a quase totalidade dos cursos visa à formação de professores, com destaque para os cursos de Pedagogia e Artes Visuais. As exceções são o curso de Administração e o de Desenvolvimento de Sistemas para Web.

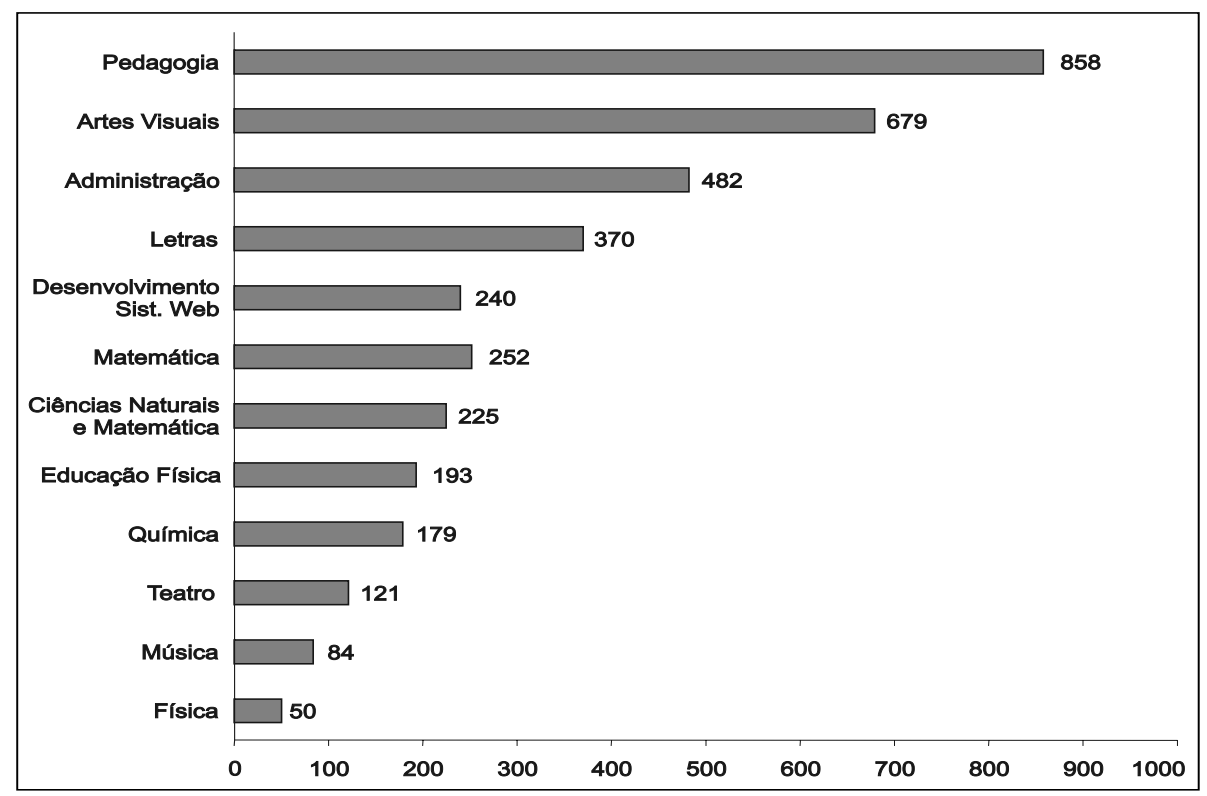

Gráfico 3 - Distribuição das vagas por curso na Região Centro-Oeste. Fonte: As autoras (2008). 
Assim como na Região Norte, na Região Centro-Oeste o Curso de Pedagogia supera todos os outros em quantidade de vagas oferecidas, o que nos permite também levantar as mesmas questões avaliativas já indicadas para a primeira região.

\section{Região Sudeste}

A Região Sudeste tem uma área de $927.286 \mathrm{~km}^{2}$ e é a de maior população no País, somando, de acordo com o Instituto Brasileiro de Geografia e Estatística (IBGE), na contagem da população (IBGE, 2008), 77.857 .758 habitantes, sendo a região com maior densidade demográfica $\left(78,09\right.$ habitantes por $\left.\mathrm{km}^{2}\right)$. A região também possui o mais alto indice de urbanização: 90,5\%. As duas maiores cidades do País encontram-se nesta região: São Paulo e Rio de Janeiro, localizadas em estados que levam os mesmos nomes. A cidade de Belo Horizonte, capital do estado de Minas Gerais, é considerada importante metrópole regional.

Economicamente, a Região é a mais desenvolvida e industrializada dentre as economias das cinco regiões brasileiras, nela se concentrando mais da metade da produção nacional. A Região consegue manter uma elevada participação no PIB industrial. Entretanto, apesar dos altos índices de desenvolvimento, a expansão desordenada, assim como o êxodo rural e a consequente desordem urbana, vêm contribuindo para o crescimento da violência que tem atingido patamares acima dos toleráveis. Ainda assim, seus indicadores sociais mostram-se os melhores do País de acordo com os dados do IBGE (2008).

Com relação à Educação Superior, a Região possui 81 Instituições de Ensino Superior públicas e 857 privadas. As públicas têm aproximadamente 400 mil estudantes matriculados, enquanto as privadas têm mais de 1 milhão de matrículas.

$\mathrm{Na}$ Região Sudeste, as instituições participantes da UAB no atendimento ao programa de EAD são: Centro Federal de Educação Tecnológica do Espirito Santo (CEFET-ES), Universidade Federal do Espírito Santo (UFES), Universidade Federal de Juiz de Fora (UFJF), Universidade Federal de Minas Gerais (UFMG), Universidade Federal de Ouro Preto (UFPO), Universidade Federal de Itajubá (UNIFEI), e Universidade Federal de São Carlos (UFSCAR).

A distribuição das vagas por Curso de Graduação na Região Sudeste pode ser vista no Gráfico 4. Como já observado, o curso de Pedagogia destaca-se em quantitativo de vagas. No entanto, cerca de metade dos cursos oferecidos não são voltados para a formação de professores. Dentre eles sobressai o de Administração, o que também ocorre em outras Regiões. Além desse curso, há uma considerável oferta de vagas para Engenharia Ambiental, Sistemas de Informação e Análise e Desenvolvimento de Sistemas. 


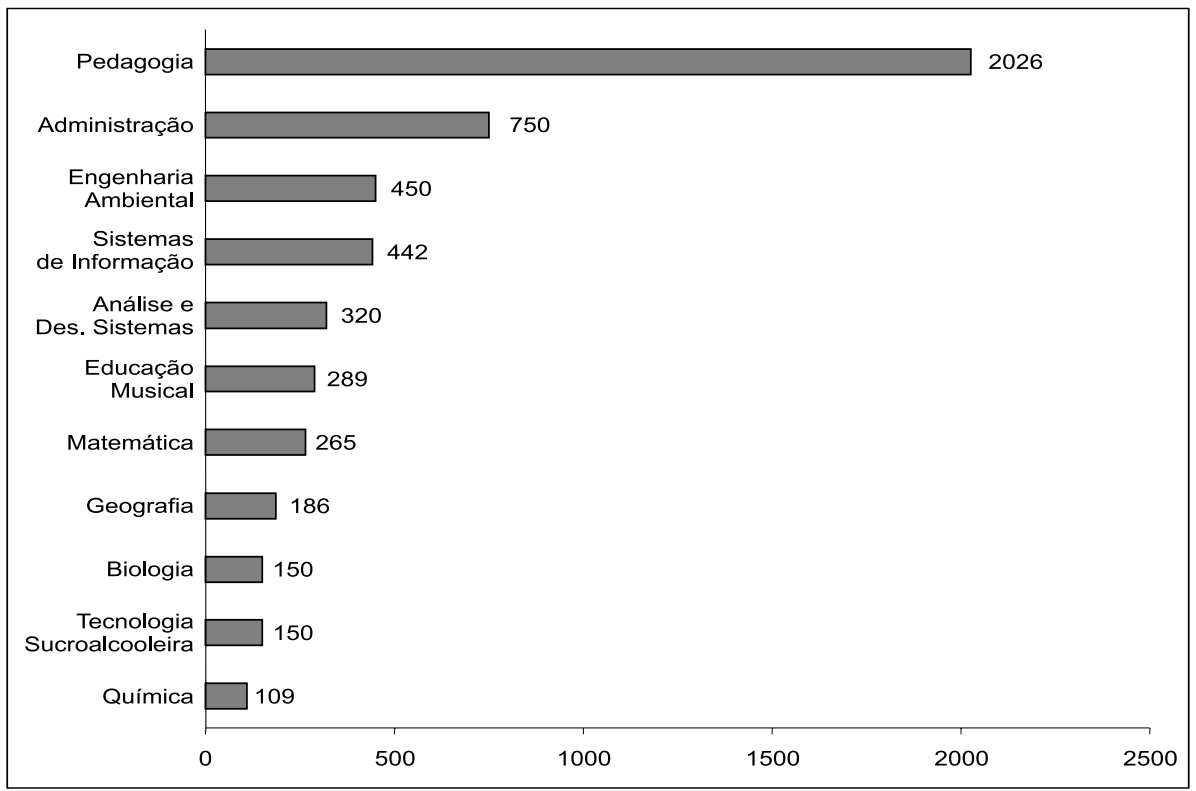

Gráfico 4 - Distribuição das vagas por curso na Região Sudeste.

Fonte: As autoras (2008).

Na Região Sudeste, o Consórcio CEDERJ (FUNDAÇÃO CECIERJ; CEDERJ, 2008), em função de sua atipicidade terá enfoque especial em artigo a ser elaborado, visto que os dados ainda estão sendo coletados. Entretanto, já se pode indicar que atualmente o Consórcio oferece um Curso de Bacharelado em Administração, um Curso Tecnológico em Sistemas de Computação e cinco Cursos de Licenciatura em Pedagogia, Matemática, Física, Química e Biologia.

Em uma primeira análise dos dados coletados nesta Região, excetuando-se o Estado do Rio de Janeiro, em função do Consórcio CEDERJ, pode-se perceber que embora o Curso de Pedagogia ofereça 2026 vagas, dos 11 cursos oferecidos, apenas 5 seguem as diretrizes governamentais no que diz respeito à prioridade um, que seria a formação de professores. Os seis demais se encontram divididos entre bacharelados e tecnológicos.

\section{Região Sul}

A Região Sul é formada pelos Estados do Paraná, Santa Catarina e Rio Grande do Sul e possui grande influência européia (principalmente italiana e alemã). É a menor das regiões, ocupando cerca de 7\% do território brasileiro. Por outro lado, sua população, de 26.973,511 habitantes, é duas vezes maior que o número de habitantes das regiões Norte e Centro-Oeste juntas. Faz fronteiras com o Uruguai ao sul, com a Argentina e o Paraguai a oeste, com a região Centro-Oeste e a região Sudeste do Brasil ao norte e com o oceano Atlântico a leste. 
Historicamente, a Região é marcada por sangrentas guerras como a Guerra dos Farrapos, a chamada Revolução Farroupilha e a mais recente Revolução Federalista.

Os indicadores sociais da Região são altos quando comparados aos das Regiões Norte e Nordeste. Os índices educacionais também se apresentam mais altos no sul do País. A Região possui 36 instituições públicas de Ensino Superior e 270 de ensino privado.

Na Região Sul, as instituições participantes da UAB no atendimento ao programa de EAD são: Universidade Federal do Rio Grande do Sul (UFRGS), Centro Federal de Educação Tecnológica de Pelotas (CEFET-RS), Fundação Universidade Federal do Rio Grande (FURG), Universidade Federal de Pelotas (UFPEL), Universidade Federal de Santa Maria (UFSM), Universidade Federal de Santa Catarina (UFSC), e Centro Federal de Educação Tecnológica de Santa Catarina (CEFET-SC).

A distribuição das vagas por Curso de Graduação na Região Sul é apresentada no Gráfico 5. Verifica-se que os cursos com maior oferta são os de Administração e de Pedagogia. Além dos cursos de Pedagogia, Letras, Matemática, Filosofia e Ciências Biológicas, há uma oferta expressiva de vagas para cursos que não têm por finalidade a formação de professores. Dentre esses, destacam-se os de Administração, Planejamento e Gestão do Desenvolvimento Rural e Ciências Contábeis.

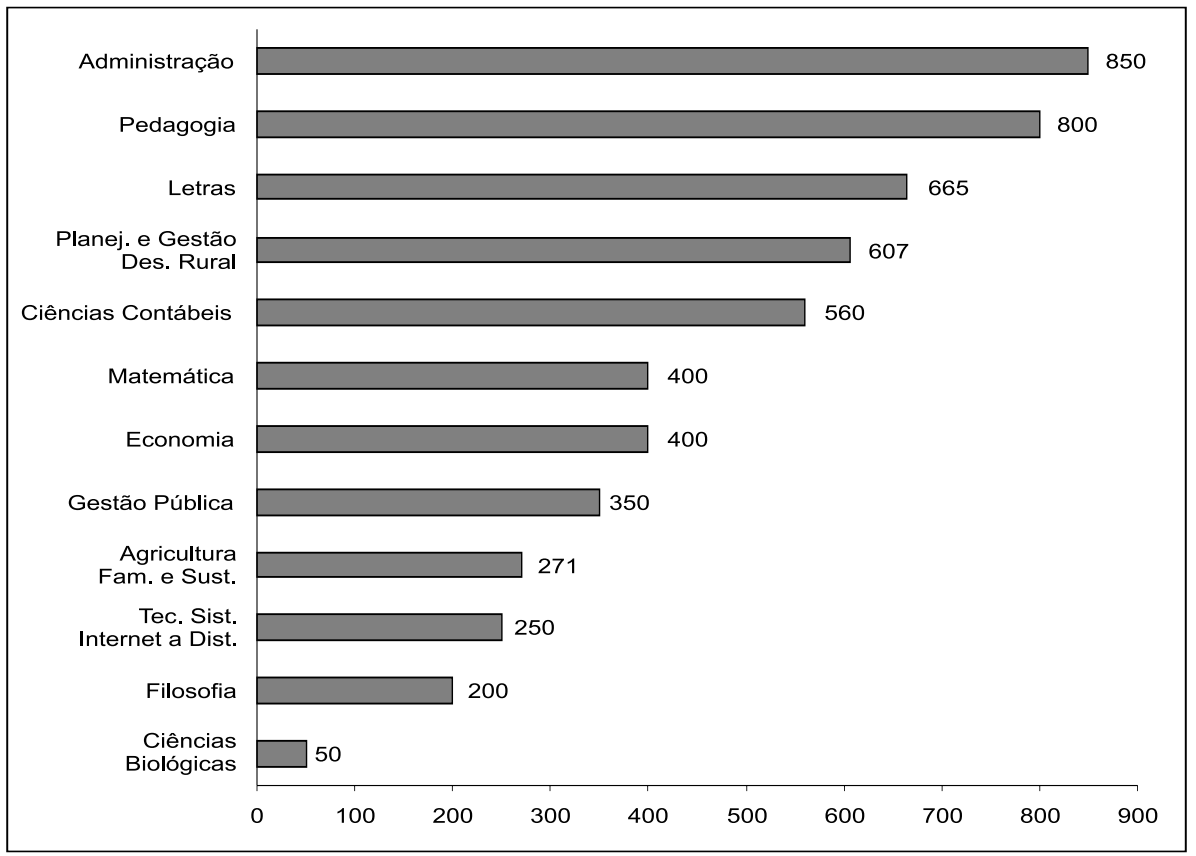

Gráfico 5 - Distribuição das vagas por curso na Região Sul. Fonte: As autoras (2008). 
Na Região Sul acontece o mesmo fenômeno da região Sudeste, ou seja, dos 12 cursos oferecidos apenas 5 são destinados à formação de professores. Mais surpreendente ainda é que a maior oferta de vagas é para o Bacharelado em Administração.

\section{Questões avaliativas}

Com o objetivo de analisar mais profundamente o estado da arte do Ensino Superior, na modalidade a distância, oferecido pelo setor público no País, foram levantadas questões avaliativas para cada região geográfica estudada. Segundo Chianca, Marino e Schiesari (2001), a formulação das perguntas, embora não se traduza em uma atividade complexa, toma tempo e demanda grande esforço por parte dos avaliadores. Neste sentido, os autores destacam que

A elaboração de perguntas é um momento-chave do processo que requer uma reflexão profunda e cuidadosa do grupo envolvido com a avaliação. Se perguntas triviais são incluídas na avaliação, corre-se o risco de ter um retorno pequeno ou mesmo nenhum retorno do investimento feito na avaliação (CHIANCA; MARINO; SCHIESARI, 2001, p. 34).

Ainda com relação à formulação de questões avaliativas, Cronbach e Shapiro (1982) postulam a existência de duas fases as quais eles chamam de divergente e convergente. $\mathrm{Na}$ fase divergente são listadas todas ou muitas das questões consideradas importantes por todos aqueles envolvidos no processo avaliativo. Já na fase convergente, a grande tarefa é selecionar dessa grande lista as questões às quais avaliação deverá responder.

Para o levantamento das questões avaliativas deste estudo, foram seguidas também as recomendações de Shadish (1994) que propõe o envolvimento do avaliador em atividades e práticas que favoreçam a utilização dos resultados da avaliação e que, acima de tudo, forcem o avaliador a fazer recomendações que venham a contribuir para a melhoria do objeto avaliado. Neste sentido, serão agora apresentadas e comentadas algumas das questões avaliativas já elencadas até a presente data.

A primeira grande questão, surgida com a avaliação diagnóstica, está diretamente ligada à Legislação: Até que ponto um projeto de "Educação a Distância" é inviabilizado por uma Lei que exige avaliação presencial para todo e qualquer Curso de Graduação? Em que medida se justifica chamar cursos semipresenciais de cursos a distância?

Outro questionamento que permeou toda a avaliação diagnóstica está relacionado com a nomenclatura utilizada em praticamente todos os cursos do Pais: Em que medida se justifica utilizar o termo "tutores" para denominar os professores que atuam em programas ditos à distância? Qual a formação dos tutores? Quem são os tutores? 
A partir destes questionamentos centrais, uma série de outras questões avaliativas emergiu e deu origem à fase divergente, citada por Cronbach e Shapiro (1982). Para se chegar às questões avaliativas que serão investigadas nas próximas fases da Prática de Avaliação, foi utilizada a matriz sugerida por Chianca, Marino e Schiesari (2001) e adaptada de Worthen, Sanders e Fitzpatrick (1997). A referida matriz é composta por critérios e possíveis perguntas avaliativas. A cada questão formulada deve-se atribuir um valor que reflita o atendimento ao critério. 0 somatório final, por coluna, na fase divergente da avaliação é um forte indicador da qualidade da questão avaliativa a ser investigada.

\section{Matriz para selecionar perguntas avaliativas ${ }^{3}$}

\begin{tabular}{|c|c|c|c|c|c|c|}
\hline \multirow[t]{2}{*}{ Critérios } & \multicolumn{6}{|c|}{$\begin{array}{l}\text { Perguntas Avaliativas } \\
\text { (fase divergente) }\end{array}$} \\
\hline & 2 & 3 & 4 & 5 & 6 & $(n)$ \\
\hline \multicolumn{7}{|c|}{ A pergunta é relevante para os principais interessados? } \\
\hline \multicolumn{7}{|c|}{$\begin{array}{l}\text { A pergunta contribui para diminuir dúvidas existentes, trata } \\
\text { de informações que não estão disponiveis no momento? }\end{array}$} \\
\hline \multicolumn{7}{|c|}{$\begin{array}{l}\text { A pergunta possibilita gerar informações importantes, que } \\
\text { podem facilitar a tomada de decisões operacionais ou de } \\
\text { política do programa? }\end{array}$} \\
\hline \multicolumn{7}{|c|}{$\begin{array}{l}\text { A pergunta está centrada em elementos críticos do programa, } \\
\text { que serão de interesse constante das pessoas e não apenas de } \\
\text { interesse momentâneo, passageiro? }\end{array}$} \\
\hline \multicolumn{7}{|c|}{$\begin{array}{l}\text { Os objetivos ou amplitude da avaliação seriam seriamente } \\
\text { comprometidos se esta pergunta fosse retirada do estudo? }\end{array}$} \\
\hline \multicolumn{7}{|c|}{$\begin{array}{l}\text { É possivel responder a esta pergunta com os métodos e as } \\
\text { tecnologias disponíveis? }\end{array}$} \\
\hline \multicolumn{7}{|c|}{$\begin{array}{l}\text { É possivel responder a esta pergunta dentro do tempo de que } \\
\text { se dispõe? }\end{array}$} \\
\hline Resultado final (somatório de respostas positivas) & & & & & & \\
\hline
\end{tabular}

Todas as questões, propostas de forma coletiva, foram listadas e analisadas para então se chegar à fase convergente do estudo, da qual se originaram questões avaliativas especificas para cada região geográfica do país.

Na região Norte, assim como na Centro-Oeste, a indagação central ficou atrelada a não existência de cursos na área ambiental em regiões cuja grande preocupação mundial está diretamente ligada à sustentabilidade. A questão norteadora seria então: em que medida a não existência de cursos no setor ambiental na Região Amazônica coaduna-se com as necessidades de uma politica educacional de sustentabilidade para essa Região?

3 Com relação ao critério referente a prazos, ficou decidido que o mesmo não seria levado em consideração na primeira fase deste estudo, em função do desenho da disciplina, que prevê etapas a serem cumpridas para cada grupo. Desta forma, seria praticamente impossível determinar, a priori, prazos para grupos de avaliadores distintos. 
Na Região Nordeste a questão que salta aos olhos é a grande oferta de vagas para curso tecnológicos na área de Sistema de Informação em detrimento de cursos de formação de professores que são, na verdade, o foco das políticas públicas no país. Assim sendo, a questão central para esta região ficou assim elaborada: Que razões justificam a grande oferta de vagas para cursos tecnológicos na área de Sistema de Informação?

$\mathrm{Na}$ Região Sudeste foram selecionadas as seguintes questões avaliativas: quais são as possíveis razões para a inexistência do Curso de Licenciatura em Geografia frente à real necessidade de professores de Geografia na Região? Até que ponto a grande oferta de vagas para Bacharelado em Administração reflete as políticas públicas na área? e finalmente, Quais seriam as possiveis razões para o alto número de vagas oferecido para Pedagogia nesta Região, tendo em vista ser esta a Região com o maior número de professores formados no País?

Na Região Sudeste, o Consórcio CEDERJ será avaliado separadamente em função de suas atipicidades frente aos outros cursos superiores existentes nas demais regiões.

As seguintes questões avaliativas foram destacadas para a região Sul: Em que medida se explica o não seguimento das diretrizes governamentais para oferta de cursos na modalidade $a$ distância, no que diz respeito à formação de professores nesta região? e Até que ponto a grande oferta de vagas para o Curso de Bacharelado em Administração está em consonância com as políticas públicas do setor?

\section{Próximos passos}

A próxima etapa da Prática de Avaliação envolverá, certamente, a definição de indicadores que são pistas que contribuem para as respostas a cada uma das questões levantadas. Para se realizar a seleção, a mais adequada possivel, dos indicadores serão utilizados os critérios técnicos propostos por Oakes (1986). As atividades a serem realizadas com o prosseguimento do estudo serão ainda definidas coletivamente envolvendo todos os participantes do grupo.

Os resultados obtidos com a avaliação diagnóstica das cinco regiões geográficas analisadas revelaram diversos fatores que podem influenciar a temática em foco neste estudo avaliativo. Esse panorama nos permite, a priori, indicar a avaliação responsiva, defendida por Stake (1975), como a abordagem avaliativa mais indicada para o prosseguimento desta avaliação. Para esse autor é fundamental que se respondam às realidades do programa e às reações cotidianas que envolvem todos os participantes do processo. Stake $(1975$, p. 14) define assim esta abordagem:

Uma avaliação educacional é responsiva quando se volta mais diretamente para as atividades do programa do que para as suas intenções; quando responde às exigências de informações dos interessados; e quando as diferentes perspectivas valorativas presentes são consideradas no relató- 
rio que fala do sucesso ou fracasso do programa.

Stake (1975) defende que os avaliadores responsivos devem ter contato com o público e interagir o mais possivel com os diversos grupos de participantes para assegurar a fidedignidade das informações recebidas. 0 avaliador responsivo deve ter mente a importância da flexibilidade para abordagens centradas no participante.

Espera-se que, ao responder às questões avaliativas já indicadas, os participantes da Prática de Avaliação elaborem de forma colaborativa materiais que venham a se tornar fontes de avaliações e pesquisas. Pretende-se que tais materiais constituamse em publicações de diferentes tipos, tais como livros e relatórios parciais e finais, a serem veiculados em diferentes mídias para diferentes públicos.

\section{Referências}

BRASIL. Lei n. 9.394, de 20 de dezembro de 1996. Estabelece as Diretrizes e Bases da Educação Nacional. Diário Oficial [da República Federativa do Brasil], Brasilia, DF, 23 dez. 1996. Disponível em: <http://www.planalto.gov.br/CCIVIL/ leis/L9394.htm>. Acesso em: jun. 2008.

CAPES. Novos pólos da UAB contribuirão para a formação de professores. Sala de Imprensa, Brasilia, DF, 12 maio 2008a. Disponível em: <http:// www.capes.gov.br/servicos/sala-de-imprensa/36-noticias/2096>. Acesso em: 22 jun. 2009.

Sobre a UAB: histórico. Brasília, DF, $2008 b$.

Disponivel em:<http://uab.capes.gov.br/index.php?option=com_contentCtview $=$ articlectid=57\&ttemid=67>. Acesso em: jun. 2008.

CHIANCA, T. K.; MARINO, E.; SCHIESARI, L. Avaliando programas sociais: conceitos, principios e práticas. In: - (Org.). Desenvolvendo a cultura de avaliação em organizações da sociedade civil. São Paulo: Global, 2001.

CRONBACH, L. J.; SHAPIRO, K. Designing evaluations of educational and social programs. San Francisco: Jossey-Bass, 1982.

FUNDAÇÃO CECIERJ; CEDERJ. Fundação Centro de Ciências e Educação Superior a Distância do Estado do Rio de Janeiro. Institucional, Rio de Janeiro, 2008. Disponível em: <http://www.cederj.edu.br/fundacaocecierj/exibe_artigo.php>. Acesso em: jun. 2008.

IBGE. Contagem da população 2007. Rio de Janeiro, 2008. Disponível em: <www.ibge.gov.br/home/estatistica/populacao/contagem2007/default.shtm>. Acesso em: 24 nov. 2008. 
IBSTPI. Evaluator competencies. State College, PA, 2006. Disponível em: <http:// www.ibstpi.org/Competencies/evaluatorcompetencies.htm>. Acesso em: 17 jun. 2008. INEP. Índice de desenvolvimento da educação básica. Brasília, DF, 2008. Disponivel em: <http://ideb.inep.gov.br/Site/>. Acesso em: 21 jun. 2008.

LAGUARDIA, J.; PORTELA, M. C.; VASCONCELOS, M. M. Avaliação em ambientes virtuais de aprendizagem. Educação e Pesquisa, São Paulo, v. 33, n. 3, p. 513-30, set./dez. 2007.

OAKES, J. Educational indicators: a guide for policymakers. New Brunswick, NJ: Rutgers University, Center for Policy Research in Education, 1986. (ED 315 920).

PORTAL BRASIL. A sua biblioteca virtual. Brasilia, DF, 2008.

Disponivel em: <http://www.portalbrasil.net>. Acesso em: 28 jun. 2008.

SHADISH, W.R. Need-based evaluation: what do you need to know to do good evaluation?. American Journal of Evaluation, Thousand Oaks, CA, v.15, n.3, p. 347-358, 1994.

SILVA, A. C.; SILVA, C. M. T. O cenário da educação superior a distância no Brasil: avaliação diagnóstica da esfera pública: livro 1. Rio de Janeiro: Fundação Cesgranrio, 2008.

SILVA, C. M. T.; SILVA, A. C. 0 desafio da aprendizagem em ambientes virtuais: da possivel mudança à provável repetição de modelos. In: CONGRESSO INTERNACIONAL DE EDUCAÇÃO A DISTÂNCIA: educação a distância e cidadania: um caminho para a justiça social, 12., 2008, Rio de Janeiro. Trabalhos apresentados... Rio de Janeiro: CREAD, 2008. Disponivel em: <http:// www.cread2008.com.br/programacao/trabalhos/1032.pdf>. Acesso em: out. 2008.

STAKE, R. E. Program evaluation, particularly responsive evaluation. Kalamazoo: Western Michigan University Evaluation Center, 1975. (Occasional paper; n. 5).

WORTHEN, B. R.; SANDERS, J. R.; FITZPATRICK, J. L. Program evaluation: alternative approaches and practical guidelines 2. ed. New York: Longman, 1997.

Recebido em: 17/03/2009

Aceito para publicação em: 25/04/2009 
